\title{
Application via mechanical dropper alleviates sufentanil-induced cough: a prospective, randomized, single-blinded trial
}

Minqiang Liu', Zhichao Li ${ }^{1}$, Song Wang ${ }^{1}$, Yong Liu' ${ }^{1}$ Xiangpeng Zhong ${ }^{1}$, Renliang $\mathrm{He}^{1^{*}}$ (D) and Fengxian Li ${ }^{2}$

\begin{abstract}
Background: It was reported that prolonging the injection time or diluting administration can reduce the incidence of opioid-induced cough. However, the incidence of sufentanil-induced cough (SIC) via a standardized infusion rate is unclear. A mechanical dropper is an infusion filtering device commonly used for intravenous degassing; it can also be used to administer special drugs due to its temporary storage and dilution effect. This study assesses the effectiveness of administration via mechanical dropper on SIC.

Methods: Two hundred patients undergoing general anesthesia were enrolled. Patients received sufentanil at a strength of $0.3 \mu \mathrm{g} \cdot \mathrm{kg}^{-1}$ either via T-connector (group C) or by mechanical dropper (group M) at $1 \mathrm{ml} \cdot \mathrm{s}^{-1}$. Cough severity was graded as none (0), mild (1-2), moderate (3-5), or severe $(>5)$, and the incidence of SIC was evaluated for $5 \mathrm{~min}$ after the start of sufentanil injection. Other adverse reactions such as hypotension, hypertension, bradycardia, tachycardia, hypoxemia, vomiting, and aspiration during the induction period of general anesthesia were also observed. The primary outcome was the incidence of SIC. The secondary outcomes were the severity of $\mathrm{SIC}$ and other adverse reactions.

Results: The incidence of SIC in group M was significantly lower than that in group C ( $2 \%$ versus $21 \%, P=0.000$ ), and the prevalence of moderately severe coughing was also statistically different (none in group $M$ versus $11 \%$ in group $C, P=0.001)$. However, there were no statistical differences in the incidence of other adverse reactions between two groups $(P>0.05)$.

Conclusion: Sufentanil application via mechanical dropper can significantly alleviate the occurrence of SIC during the induction phase of total intravenous general anesthesia. This method is simple, safe, and reliable, and has wide prospective application for clinical use.
\end{abstract}

Trial registration: Chinese Clinical Trial Register, ChiCTR-IOR-17011561. Registered on 3 June 2017.

Keywords: Sufentanil, Cough, General anesthesia, Mechanical dropper

\footnotetext{
* Correspondence: szherenliang@163.com

'Department of Anesthesiology, Shenzhen Third People's Hospital, No. 29

Bulan Road, Longgang district, Shenzhen 518112, Guangdong, China

Full list of author information is available at the end of the article
}

(c) The Author(s). 2019 Open Access This article is distributed under the terms of the Creative Commons Attribution 4.0 International License (http://creativecommons.org/licenses/by/4.0/), which permits unrestricted use, distribution, and reproduction in any medium, provided you give appropriate credit to the original author(s) and the source, provide a link to the Creative Commons license, and indicate if changes were made. The Creative Commons Public Domain Dedication waiver (http://creativecommons.org/publicdomain/zero/1.0/) applies to the data made available in this article, unless otherwise stated. 


\section{Background}

Opioid-induced cough (OIC) is a common phenomenon during the induction of general anesthesia, and is normally considered to be temporary and not serious [1]. However, sudden, irritating cough may lead to hypertension, tachycardia, anoxia, pneumothorax, and other, even life-threatening, conditions [2, 3], especially for patients suffering from cardiopulmonary dysfunction $[4,5]$. Sufentanil is a potent opioid commonly used in clinical anesthesia for its strong analgesic property $[6,7]$. The incidence of sufentanil-induced cough (SIC) during the induction of anesthesia has been reported by different studies as being in a range from 16 to $47 \%$ [8-10]. Although SIC occurrence can be prevented using pretreatment with drugs such as lidocaine [11], dexmedetomidine [12], or dezocine [13], the existence of notable drug-related side effects has limited their use $[14,15]$. Therefore, developing a simple, effective, and nonpharmacological method to counter SIC would be of considerable clinical significance.

A mechanical dropper, also known as a Murphy drip, an infusion set drip cup, or a drip chamber, is an infusion filtering apparatus with a variety of applications. In daily medical care, it can be used for intravenous degassing, observation of the infusion rate, or administration of special drugs when complications are associated with other methods of injection since there is a long intravenous fluid line from this apparatus to the end of the infusion set $[16,17]$. In this prospective and randomized study, we compared the effect of sufentanil application via T-connector or mechanical dropper on SIC, hypothesizing that the latter approach can help reduce the incidence of SIC.

\section{Methods}

\section{Study design and setting}

The study was approved by the Medical Ethics Committee of the Shenzhen Third People's Hospital, Shenzhen, Guangdong, China, on 10 April 2017 (approval number: 2017-059), and was registered in the Chinese Clinical Trial Register (http://www.chictr.org.cn/index.aspx; Registration Number: ChiCTR-IOR-17011561). Written informed consent regarding the study protocol was obtained from all eligible patients. Patients undergoing scheduled general anesthesia who were both aged 18-65 years and classified by the American Society of Anesthesiologists (ASA) physical status classification scheme as belonging to classes I or II were enrolled. The exclusion criteria were those older than 65 years or younger than 18 years, pregnancy, body mass index $(\mathrm{BMI})>30 \mathrm{~kg} / \mathrm{m}^{2}$, history of bronchial asthma, chronic obstructive pulmonary disease, smoking, upper airway infection in the last 2 weeks, a history of circulatory system diseases or disorders, treatment with angiotensin-converting enzyme inhibitors, impaired kidney or liver function, known hypersensitivity to general anesthetics or opioids, drug abuse, and those who were anticipated to have difficult airway intubation.

\section{Sample size calculation}

The estimation of sample size was based on a $16 \%$ reported incidence of SIC following an induction dose of sufentanil of $0.3 \mu \mathrm{g} \cdot \mathrm{kg}^{-1}$ [9]. A previous study reported a reduction of fentanyl-induced cough via mechanical dropper of approximately $84 \%$ [17], so we assumed that this simple method would cause at least an $80 \%$ decrease in the incidence of SIC. At $\alpha=0.05$ and $\beta=0.10$, we needed to enroll 93 patients in each group; therefore, we recruited 200 patients to account for possible reduction in sample size due to patients dropping out. The structure of the study is illustrated in Fig. 1.

\section{Randomization and blinding}

Using computer-generated tables of random numbers, patients were assigned to two groups, each containing 100 cases. If a patient's assigned random number was odd, the patient was assigned to the control group (group C); if it was even, the patient was assigned to the mechanical dropper group (group M). During the general anesthesia induction period, the anesthesiologist giving the anesthetics was cognizant of the patients' group assignment, but the occurrence of SIC and other parameters was observed and recorded by another anesthesiologist who was not aware of which group the patient had been assigned to and did not take part in the implementation of anesthesia.

\section{Anesthesia and monitoring}

All patients fasted for $10 \mathrm{~h}$, and no premedication was given before this study. After the patients' admission, an oxygen gas flow of $2 \mathrm{~L} \cdot \mathrm{min}^{-1}$ was given via facial mask. The electrocardiogram (ECG), heart rate (HR), non-invasive blood pressure (NIBP), mean arterial pressure (MAP), pulse oxygen saturation $\left(\mathrm{SPO}_{2}\right)$, end-tidal carbon dioxide partial pressure $\left(\mathrm{P}_{\mathrm{ET}} \mathrm{CO}_{2}\right)$, axillary temperature $(\mathrm{T})$, and bispectral index (BIS) were monitored continuously throughout the procedure. Peripheral venous access was secured using a $20-\mathrm{G}$ venous catheter on the dorsal hand, and normal saline was infused at a rate of $250 \mathrm{ml} \cdot \mathrm{h}^{-1}$ via micro-adjustment of the infusion apparatus (Fig. 2). During the induction phase of general anesthesia, the drip chamber was preloaded with $4 \mathrm{ml}$ of liquid to prevent air from entering the blood vessels, and patients received an injection of sufentanil at a concentration of $0.3 \mu \mathrm{g} \cdot \mathrm{kg}^{-1}$ (sufentanil citrate, $5 \mu \mathrm{g} \cdot \mathrm{ml}^{-1}$, diluted with normal saline; Yichang Humanwell Pharmaceutical Co. Ltd, Hubei, China). In group C, sufentanil was injected at a rate of $1 \mathrm{ml} \cdot \mathrm{s}^{-1}$ via T-connector near the venous catheter, while the same volume of normal saline was added to the mechanical dropper at a similar rate. In group $M$, sufentanil was injected into the dropper and 


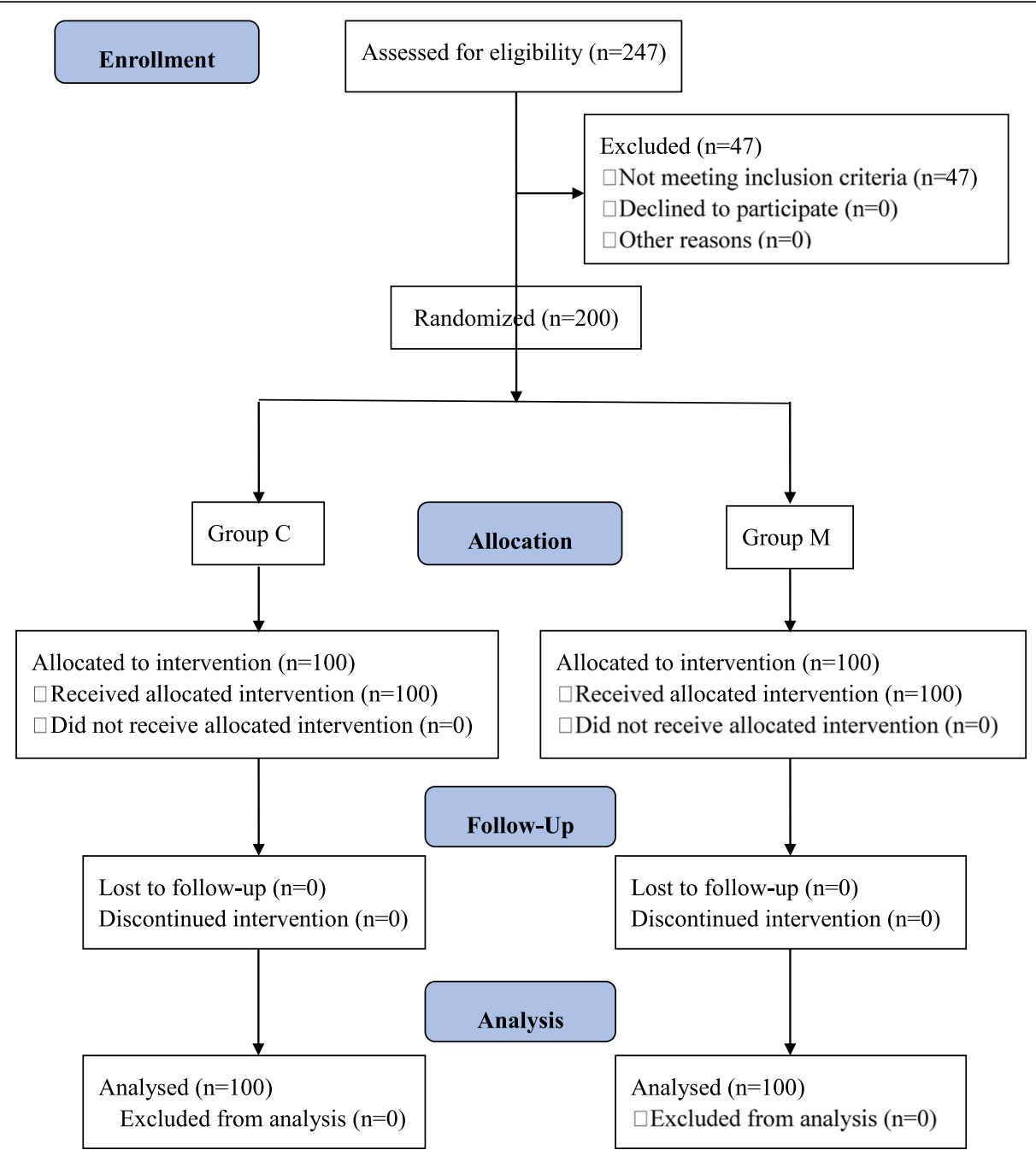

Fig. 1 Flow diagram illustrating the structure of the study

normal saline into the T-connector at $1 \mathrm{ml} \cdot \mathrm{s}^{-1}$. Five minutes after sufentanil administration, the degree of neuromuscular blockade (NMB) was measured, and a sequence of midazolam $0.05 \mathrm{mg} \cdot \mathrm{kg}^{-1}$ (Midazolam Injection; Nhwa Pharmaceutical Co. Ltd, Jiangsu, China), propofol $1.0 \mathrm{mg}$ $\sim 1.5 \mathrm{mg} \cdot \mathrm{kg}^{-1}$ (Propofol Medium and Long Chain Fat Emulsion Injection; Fresenius Kabi Austria $\mathrm{GmbH}$, Austria), and cisatracurium $0.15 \mathrm{mg} \cdot \mathrm{kg}^{-1}$ (Cisatracurium Besilate for Injection; Hengrui Medicine Co. Ltd, Jiangsu, China) were injected via T-connector (at 30-s intervals). Endotracheal intubation was then conducted when the bispectral index system baseline remained between 40 and 60 , and the first twitch response of a train-of-four stimulation fell to 0 (repeated $>3$ times).

\section{Data collection}

Any episode of cough within the 5-min period after the start of sufentanil injection was classified as SIC. The severity of SIC was graded as none (no cough), mild (1-2 instances of cough), moderate (coughing with 3-4 instances), or severe (persistent cough, 5 or more instances) [18]. Vital signs such as the MAP, HR, and $\mathrm{SpO}_{2}$ were recorded every $2 \mathrm{~min}$ during anesthesia induction (from sufentanil infusion to $5 \mathrm{~min}$ after endotracheal intubation). Other adverse reactions such as hypotension (MAP decreased over $20 \%$ or NIBP $\leq 90 / 60 \mathrm{mmHg}$ ) [19, 20], hypertension (MAP increased over $20 \%$ or NIBP $\geq 140 / 90$ $\mathrm{mmHg}$ ) [21, 22], bradycardia (HR $\leq 50$ beats/min) [23], tachycardia ( $\mathrm{HR} \geq 100$ beats/min) [24], hypoxemia $\left(\mathrm{SpO}_{2}\right.$ $<90 \%$ ) [25], vomiting (ejecting the contents of the stomach through the mouth) [26], and aspiration (liquid or solid material into the trachea or lung) [27] during the induction period were also recorded.

\section{Outcomes}

The primary outcome was the incidence of SIC. The secondary outcomes were the severity of SIC and other adverse 


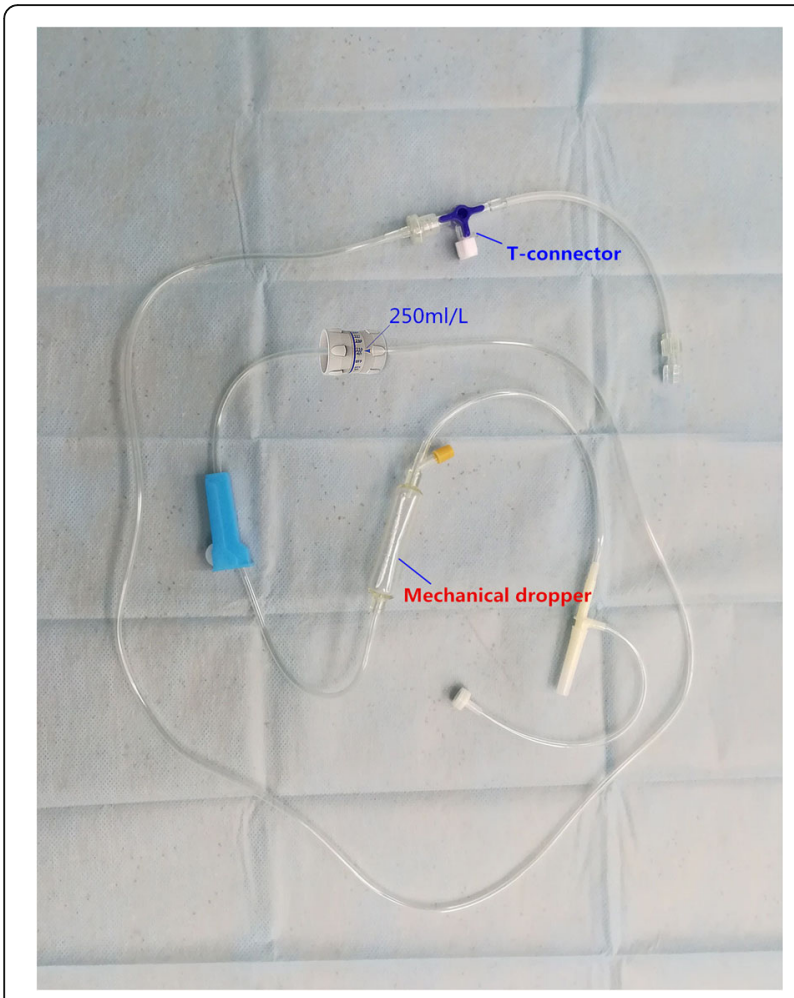

Fig. 2 Infusion apparatus: micro-adjustment, mechanical dropper, and T-connector

reactions, including hypotension, hypertension, bradycardia, tachycardia, hypoxemia, vomiting, and aspiration.

\section{Statistical analysis}

Statistical analyses were performed using IBM SPSS 13.0 (IBM Inc., Chicago, IL, USA). Data are presented as number or mean \pm standard deviation. Group comparisons about age, weight, and height were analyzed using independent $t$ test. The frequency of SIC was analyzed by Mann-Whitney $U$ test. Between-group comparisons of demographic proportions and the prevalence of adverse reactions were performed using chi-square or Fisher's exact test. $P<0.05$ was considered statistically significant.

\section{Results}

A total of 247 patients undergoing general anesthesia were initially assessed for eligibility in this study from July 3, 2017 to December 15, 2017. Forty-seven patients were excluded: 11 patients suffering from upper airway infection in the last 2 weeks, seven patients due to BMI > $30 \mathrm{~kg} / \mathrm{m}^{2}, 12$ patients due to hypertension, three patients suffering from hypotension, 10 patients due to tachycardia, and four patients for bradycardia. No severe adverse event leading to a termination of the study was observed. Therefore, altogether 200 patients (100 cases in each group) were enrolled in this research (Fig. 1).

\section{Demographic profile}

For sex, age, mean weight, and mean height, the demographic profiles of group $C$ and group $M$ were not statistically different $(P>0.05)$ (Table 1$)$.

\section{Incidence and severity of SIC}

The overall incidence of SIC in group $M$ was significantly lower than that in group $\mathrm{C}(2 \%$ of cases in group $M$ versus $21 \%$ of cases in group $C, P=0.000$ ), and the severity of moderate SIC was also statistically different (no cases in group $M$ versus $11 \%$ of cases group $C, P$ $=0.001)$. Furthermore, no cases in group $M$ suffered from severe cough (Table 2).

\section{Other adverse reactions}

There were no statistical differences in the prevalence of hypotension, hypertension, bradycardia, or tachycardia between the two groups $(P>0.05)$. No patient suffered from hypoxemia, vomiting, or aspiration during the general anesthesia induction period (Table 3).

\section{Discussion}

The mechanisms responsible for SIC are complicated, and include low compliance of the chest wall, inhibition of central sympathetic activity, histamine release, neurogenic inflammation, and tracheal hypersensitivity reaction, among others [28-31]. In previous studies, it was reported that the incidence of SIC was dose related [10, 32], thus reducing the dosage of sufentanil, diluting it, or prolonging the injection time may help to alleviate SIC. However, excessive medication dilution or a long series of manual injection times may reduce the adherence of anesthesiologists, even the controllability of anesthesia. Therefore, finding a simple way to treat SIC without affecting the quality of anesthesia is highly desirable.

Our study evaluates an ordinary method to apply sufentanil via mechanical dropper. Here, we found that our procedure successfully reduced SIC during total intravenous general anesthesia without any other medical treatment required during induction. There are three possible explanations for this inhibitory effect. First, when sufentanil was added to the mechanical dropper, it was diluted by the original liquid present in

Table 1 Demographics of the two study groups

\begin{tabular}{llll}
\hline Item & Group C & Group M & $P$ \\
\hline Sex (male/female) & $45 / 55$ & $41 / 59$ & 0.568 \\
Age (years) & $38 \pm 11$ & $39 \pm 10$ & 0.559 \\
Weight (kg) & $59 \pm 9$ & $58 \pm 8$ & 0.457 \\
Height (cm) & $163 \pm 7$ & $162 \pm 7$ & 0.313 \\
\hline
\end{tabular}

Note: Group C, sufentanil injected at a rate of $1 \mathrm{ml} \cdot \mathrm{s}^{-1}$ via T-connector near the venous catheter, while the same volume of normal saline was added to the mechanical dropper at a similar rate; group $\mathrm{M}$, sufentanil injected into the dropper and normal saline into the T-connector at $1 \mathrm{ml} \cdot \mathrm{s}^{-1}$ 
Table 2 Incidence and severity of SIC: primary outcome of the study

\begin{tabular}{llll}
\hline SIC incidence (\%) & Group C & Group M & $P$ \\
\hline None & 79 & $98^{* *}$ & 0.000 \\
Mild & 8 & 2 & 0.052 \\
Moderate & 11 & $0^{* *}$ & 0.001 \\
Severe & 2 & 0 & 0.095 \\
Total incidence & 21 & $2^{* *}$ & 0.000
\end{tabular}

Note: Group C, sufentanil injected at a rate of $1 \mathrm{ml} \cdot \mathrm{s}^{-1}$ via T-connector near the venous catheter, while the same volume of normal saline was added to the mechanical dropper at a similar rate; group $\mathrm{M}$, sufentanil injected into the dropper and normal saline into the T-connector at $1 \mathrm{ml} \cdot \mathrm{s}^{-1}$. SIC sufentanil-induced cough

Compared with group $C,{ }^{*} P<0.05,{ }^{* *} P<0.01$

the dropper, the fluid coming from the infusion bag, and the mixture continuously dropping down to the flow tube [17]. In this research, the average patient weight in both groups was approximately $60 \mathrm{~kg}$, with an induction dose of sufentanil of $0.3 \mu \mathrm{g} \cdot \mathrm{kg}^{-1}$ and an initial concentration of $5 \mu \mathrm{g} \cdot \mathrm{ml}^{-1}$, the average dosage was around $18 \mu \mathrm{g}$, and the mean volume was $3.6 \mathrm{ml}$. Since there was $4 \mathrm{ml}$ of liquid in the mechanical dropper and $10 \mathrm{ml}$ within the infusion line below, and continuous fluid coming from the infusion bottle, the mean concentration of sufentanil arriving in the blood vessels was less than $1 \mu \mathrm{g} \cdot \mathrm{ml}^{-1}$. As a result, the direct stimulation of sufentanil on the circulatory system was reduced. Second, accompanying continuous dilution, the osmolality and $\mathrm{pH}$ of sufentanil became close to the normal saline solution before entering the peripheral veins through a long intravenous fluid line. As a result, the stimulation from the vein to irritant receptors in tracheal smooth muscle tissues and $\mathrm{C}$ fiber receptors in pulmonary vessels was reduced, and the sudden vocal cord closure triggered by laryngeal muscle spasticity was thereby alleviated [28, 31]. Third, the drug infusion rate was limited via a long fluid line. Considering the differences in vascular conditions between individuals, we used micro-adjustments to standardize the infusion rate at $250 \mathrm{ml} \cdot \mathrm{h}^{-1}$; with an

Table 3 Other adverse reactions: secondary outcomes of the study

\begin{tabular}{|c|c|c|c|}
\hline Item & Group C & Group M & P \\
\hline Hypotension (\%) & 19 & 17 & 0.713 \\
\hline Hypertension (\%) & 6 & 7 & 0.774 \\
\hline Bradycardia (\%) & 14 & 12 & 0.674 \\
\hline Tachycardia (\%) & 9 & 9 & 1.000 \\
\hline Hypoxemia (\%) & 0 & 0 & 1.000 \\
\hline Vomiting (\%) & 0 & 0 & 1.000 \\
\hline Aspiration (\%) & 0 & 0 & 1.000 \\
\hline
\end{tabular}

initial liquid volume of $14 \mathrm{ml}$ from the dropper to the venous catheter, it took about $5 \mathrm{~min}$ for the sufentanil to completely enter the patient's body. For this reason, the actual injection time of the sufentanil was prolonged significantly, resulting in a much lower peak plasma concentration. Consequently, dose-related adverse reactions such as cough were alleviated, and a lower incidence of severe SIC was observed. Moreover, we found no differences in the prevalence of circulatory or respiratory complications such as hypotension, hypertension, bradycardia, tachycardia, or hypoxemia between the control and experimental groups, which suggests that sufentanil application via mechanical dropper is not associated with these serious side effects.

There are some limitations to our findings here. First, we set a low infusion rate to avoid individual differences in vascular conditions from affecting the treatment. Consequently, the total sufentanil infusion time was much longer in group $\mathrm{M}$ than is typical in clinical practice. Second, since the onset time of intravenous sufentanil was $1-3 \mathrm{~min}$ and the time to peak effect was around 5 min [7], we evaluated the incidence of SIC within the 5 -min period after the start of sufentanil injection. However, the actual injection time in group $\mathrm{M}$ was about 5 min, meaning SIC may still appear several seconds to minutes after the real injection was finished. A longer observation period of SIC, such as 10 min after the start of sufentanil injection, could prevent the possible bias. Third, the interactive effects of other medications often given with sufentanil were not tested. Sedatives such as midazolam or propofol were often administered before the use of opioids to reduce the patient's discomfort, and our treatments did not include these. Finally, the average age of patients enrolled in our research was around 40 years, but age is believed to be an important confounding factor in OIC [33]. Elders, children, infants, and larger-scale treatment that also assessed the optimal sequence of drug administration would be beneficial to further verify the effectiveness of the application of sufentanil via mechanical dropper.

\section{Conclusions}

This study reports that the application of sufentanil via mechanical dropper can effectively alleviate SIC during total intravenous general anesthesia induction. This method is simple, safe, and reliable, and is suitable for poorly equipped hospitals in developing countries.

\section{Abbreviations}

ASA: American Society of Anesthesiologists; BIS: Bispectral index; ECG: Electrocardiogram; HR: Heart rate; MAP: Mean arterial pressure; NIBP: Non-invasive blood pressure; NMB: Neuromuscular blockade; $\mathrm{P}_{\mathrm{ET}} \mathrm{CO}_{2}$ : End-tidal carbon dioxide partial pressure; $\mathrm{SIC}$ : Sufentanil-induced cough; $\mathrm{SPO}_{2}$ : Pulse oxygen saturation; T: Temperature 


\section{Acknowledgements}

Thanks to Journal of Zhejiang University English Polishing Service (http:// www.jzus.zju.edu.cn/polish.php) for the English edit in this study.

\section{Funding}

Not applicable.

\section{Availability of data and materials}

This study was recorded on ResMan Research Manager:

http://www.medresman.org/pub/cn/proj/projectshshow.aspx?proj=214.

\section{Authors' contributions}

$M L$ and $Z \mathrm{~L}$ conceived the project and helped design the study. ML, ZL, and SW performed general anesthesia and drafted the manuscript. $Y L$ and $X Z$ collected and analyzed the data. FL contributed to and revised the manuscript. RH accepted direct responsibility for the manuscript that resulted from this study. All authors approved the final submission.

\section{Ethics approval and consent to participate}

This study was approved by the Medical Ethics Committee of Shenzhen third People's Hospital (No.29 Bulan Road, Longgang district, Shenzhen, Guangdong, China, approval number: 2017-059, date: 2017-4-10).

Written informed consent was obtained and documented for all participants.

\section{Consent for publication}

Not applicable.

\section{Competing interests}

The authors declare that they have no competing interests.

\section{Publisher's Note}

Springer Nature remains neutral with regard to jurisdictional claims in published maps and institutional affiliations.

\section{Author details}

'Department of Anesthesiology, Shenzhen Third People's Hospital, No. 29 Bulan Road, Longgang district, Shenzhen 518112, Guangdong, China. ${ }^{2}$ Department of Anesthesiology, Zhujiang Hospital of Southern Medical University, No. 253 Middle Industrial Avenue, Haizhu district, Guangzhou 518112, Guangdong, China.

Received: 16 August 2018 Accepted: 1 March 2019

Published online: 15 March 2019

\section{References}

1. Schäfer M, Keilig S, Brack A, Kranke P. Opioid induced cough: do we know its pathophysiology and can it be eliminated? Anasthesiol Intensivmed Notfallmed Schmerzther. 2010;45(3):170-3. https://doi.org/10.1055/s-00301249398.

2. Shields MD, Thavagnanam S. The difficult coughing child: prolonged acute cough in children. Cough. 2013;9(1):11. https://doi.org/10.1186/1745-9974-911.

3. Nguyen TT, Higashi T, Kambayashi Y, Anyenda EO, Michigami Y, Hara J, et al. A longitudinal study of association between heavy metals and itchy eyes, coughing in chronic cough patients: related with non-immunoglobulin $\mathrm{E}$ mediated mechanism. Int J Environ Res Public Health. 2016;13(1):110. https://doi.org/10.3390/ijerph13010110.

4. Faruqi S, Murdoch RD, Allum F, Morice AH. On the definition of chronic cough and current treatment pathways: an international qualitative study. Cough. 2014;10:5. https://doi.org/10.1186/1745-9974-10-5.

5. Lim K, Lee SK, Lee HM, Park EY, Kim MH, Kim YS, et al. Aspiration pneumonia caused by fentanyl-induced cough — a case report. Korean J Anesthesiol. 2013;65(3):251-3. https://doi.org/10.4097/kjae.2013.65.3.251.

6. Zhang K, Li M, Peng XC, Wang LS, Dong AP, Shen SW, et al. The protective effects of sufentanil pretreatment on rat brains under the state of cardiopulmonary bypass. Iran J Pharm Res. 2015;14(2):559-66 PMID: 25901164 PMCID: PMC4403073.

7. Song IK, Lee JH, Jung S, Kim JT, Kim HS. Estimation of the plasma effect site equilibration rate constant of sufentanil in children using the time to peak effect of heart rate and blood pressure. Indian J Pharmacol. 2015:47(4):3604. https://doi.org/10.4103/0253-7613.161251.
8. Shen JC, Xu JG, Zhou ZQ, Liu HJ, Yang JJ. Effect of equivalent doses of fentanyl, sufentanil, and remifentanil on the incidence and severity of cough in patients undergoing abdominal surgery: a prospective, randomized, double-blind study. Curr Ther Res Clin Exp. 2008;69(6):480-7. https://doi.org/10.1016/j.curtheres.2008.12.002.

9. Agarwal A, Gautam S, Nath SS, Gupta D, Singh U. Comparison of the incidence and severity of cough induced by sufentanil and fentanyl: a prospective, randomised, double-blind study. Anaesthesia. 2007:62(12):12302. https://doi.org/10.1111/j.1365-2044.2007.05249.x.

10. An L, Gui B, Su Z, Zhang Y, Liu HL. Magnesium sulfate inhibits sufentanilinduced cough during anesthetic induction. Int J Clin Exp Med. 2015;8(8): 13864-8 PMCID: PMC4613024.

11. Li SY, LI P, Ni J, Luo D. Different interventions in preventing opioid-induced cough: a meta-analysis. J Clin Anesth. 2016;34:440-7. https://doi.org/10. 1016/j.jclinane.2016.05.034.

12. Sun S, Huang SQ. Effects of pretreatment with a small dose of dexmedetomidine on sufentanil-induced cough during anesthetic induction. J Anesth. 2013;27(1):25-8. https://doi.org/10.1007/s00540-012-1470-y.

13. Liu XS, Xu GH, Shen QY, Zhao Q, Cheng XQ, Zhang J, et al. Dezocine prevents sufentanil-induced cough during general anesthesia induction: a randomized controlled trial. Pharmacol Rep. 2015;67(1):52-5. https://doi.org/ 10.1016/j.pharep.2014.08.004

14. Sun $L$, Guo R, Sun $L$. The impact of prophylactic intravenous lidocaine on opioid-induced cough: a meta-analysis of randomized controlled trials. J Anesth. 2014;28(3):325-33. https://doi.org/10.1007/s00540-013-1732-3.

15. Thompson KR, Rioja E. Effects of intravenous and topical laryngeal lidocaine on heart rate, mean arterial pressure and cough response to endotracheal intubation in dogs. Vet Anaesth Analg. 2016;43(4):371-8. https://doi.org/10. 1111/vaa.12303.

16. Liu F, Chen D, Liao Y, Diao L, Liu Y, Wu M, et al. Effect of intrafix ${ }^{\circledast}$ safeset infusion apparatus on phlebitis in a neurological intensive care unit: a casecontrol study. J Int Med Res. 2012;40(6):2321-6. https://doi.org/10.1177/ 030006051204000630.

17. Liu MQ, Li FX, Han YK, He JY, Shi HW, Liu L, et al. Administration of fentanyl via a slow intravenous fluid line compared with rapid bolus alleviates fentanyl-induced cough during general anesthesia induction. J Zhejiang Univ Sci B. 2017;18(11):955-62. https://doi.org/10.1631/jzus.B1600442.

18. Saleh AJ, Zhang L, Hadi SM, Ouyang W. A priming dose of intravenous ketamine-dexmedetomidine suppresses fentanyl-induced coughing: a double-blind, randomized, controlled study. Ups J Med Sci. 2014;119(4):3337. https://doi.org/10.3109/03009734.2014.968270.

19. Kalezic N, Stojanovic M, Ladjevic N, Markovic D, Paunovic I, Palibrk I, et al. Risk factors for intraoperative hypotension during thyroid surgery. Med Sci Monit. 2013;19:236-41. https://doi.org/10.12659/MSM.883869.

20. Walsh M, Devereaux PJ, Garg AX, Kurz A, Turan A, Rodseth RN, et al. Relationship between intraoperative mean arterial pressure and clinical outcomes after noncardiac surgery: toward an empirical definition of hypotension. Anesthesiology. 2013;119(3):507-15. https://doi.org/10.1097/ aln.0b013e3182a10e26.

21. O'Shaughnessy MA, Adams JE. Perioperative management of hypertension in hand surgery patients. J Hand Surg Am. 2015;40(8):1684-7. https://doi. org/10.1016/j.jhsa.2015.03.027.

22. Dewdney A, Cunningham D, Barbachano Y, Chau I. Correlation of bevacizumab-induced hypertension and outcome in the BOXER study, a phase II study of capecitabine, oxaliplatin (CAPOX) plus bevacizumab as peri-operative treatment in 45 patients with poor-risk colorectal liver-only metastases unsuitable for upfront resection. Br J Cancer. 2012;106(11):171821. https://doi.org/10.1038/bjc.2012.152.

23. Trappe HJ. ECG results: tips and tricks for the correct diagnosis: bradycardia and tachycardia rhythmdisorders. Herz. 2018;43(2):177-94. https://doi.org/10. 1007/s00059-018-4684-4.

24. Kurokochi N. Age-corrected intraoperative tachycardia correlates with postoperative electrocardiographic alterations. J Anesth. 2001;15:11-6. https://doi.org/10.1007/s005400170045.

25. Rozé H, Lafargue M, Ouattara A. Case scenario: Management of intraoperative hypoxemia during one-lung ventilation. Anesthesiology. 2011 114(1):167-74. https://doi.org/10.1097/aln.0b013e3182023ed3.

26. Shinpo K, Hirai Y, Maezawa H, Totsuka Y, Funahashi M. The role of area postrema neurons expressing $\mathrm{H}$-channels in the induction mechanism of nausea and vomiting. Physiol Behav. 2012;107(1):98-103. https://doi.org/10. 1016/j.physbeh.2012.06.002. 
27. Nason KS. Acute intraoperative pulmonary aspiration. Thorac Surg Clin. 2015;25(3):301-7. https://doi.org/10.1016/j.thorsurg.2015.04.011.

28. Yu H, Yang XY, Zhang X, Li Q, Zhu T, Wang Y, et al. The effect of dilution and prolonged injection time on fentanyl-induced coughing. Anaesthesia. 2007;62(9):919-22. https://doi.org/10.1111/j.1365-2044.2007.05147.x.

29. Rajan S, Malayil GJ, Varghese R, Kumar L. Comparison of usefulness of ketamine and magnesium sulfate nebulizations for attenuating postoperative sore throat, hoarseness of voice, and cough. Anesth Essays Res. 2017;11(2):287-93. https://doi.org/10.4103/0259-1162.181427.

30. Yin N, Xia J, Cao YZ, Lu X, Yuan J, Xie J. Effect of propofol combined with opioids on cough reflex suppression in gastroscopy: study protocol for a double-blind randomized controlled trial. BMJ Open. 2017;7(9):e014881. https://doi.org/10.1136/bmjopen-2016-014881.

31. He J, Zhu L, Zhu H, Gu X, Li P, Yang Y, et al. Dose selection of central or peripheral administration of sufentanil affect opioid induced cough?: a prospective, randomized, controlled trial. BMC Anesthesiol. 2018;18(1):38. https://doi.org/10.1186/s12871-018-0502-z.

32. Chung DH, Kim NS, Lee MK, Jo HK. The effect and optimal dose of sufentanil in reducing injection pain of microemulsion propofol. Korean J Anesthesiol. 2011;60(2):83-9. https://doi.org/10.4097/kjae.2011.60.2.83.

33. Han Jl, Lee $\mathrm{H}, \mathrm{Kim} \mathrm{CH}$, Lee GY. The frequency of fentanyl induced cough in children and its effects on tracheal intubation. J Clin Anesth. 2010;22(1):3-6. https://doi.org/10.1016/j.jclinane.2009.01.019.

Ready to submit your research? Choose BMC and benefit from:

- fast, convenient online submission

- thorough peer review by experienced researchers in your field

- rapid publication on acceptance

- support for research data, including large and complex data types

- gold Open Access which fosters wider collaboration and increased citations

- maximum visibility for your research: over $100 \mathrm{M}$ website views per year

At $\mathrm{BMC}$, research is always in progress.

Learn more biomedcentral.com/submissions 